\title{
DISSIDÊNCIAS CRIANCEIRAS: INVOLUÇÃO CRIADORA EM SALA DE AULA
}

\author{
CHILDREN DISSIDENCES: \\ CREATOR INVOLUTION IN THE CLASSROOM
}

\begin{abstract}
Edilma de Souza
Doutoranda no Programa de Pós-graduação em Educação da Universidade Federal de Mato Grosso; Professora da Educação Básica na Secretaria de Estado de Educação de Mato Grosso; Cuiabá - Mato Grosso - Brasil. edilmasz84@gmail.com

Silas Borges Monteiro Doutor em Educação pela Universidade de São Paulo; Professor no Programa de Pós-Graduação em Educação da Universidade Federal de Mato Grosso; Cuiabá - Mato Grosso - Brasil. silasbmonteiro@gmail.com
\end{abstract}

\begin{abstract}
Resumo: Este texto traz fragmentos de movimentos de pesquisa em educação. Os movimentos são marcados por leituras e escrituras agitadoras de ideias. A pesquisa abraça a filosofia da diferença e o pensamento de Deleuze, Butler e Corazza entre possíveis planos de composição na angústia de problematizar as performatividades de gêneros que constituem vidas, em especial o falogocentrismo. Para tanto, realizou-se experimentações investigativas com crianças que frequentam o ensino fundamental. As experimentações são experiências não-preexistentes, inventadas no acontecimento do cotidiano escolar. Saímos da história para entrar na vida, a vida enquanto afirmação e vontade de potência que reverbera sistemas binários de dominação. Assim, encontramos dissidências crianceiras quanto aos atos de performatividades de gêneros por meio de oficinas de escrileituras que resultaram em escritas-leituras críticas e criadoras de novos modos de pensar, ver e sentir a vida e a Educação.
\end{abstract}

Palavras-chave: Crianças. Dissidências. Educação. Escritas-leituras. Performatividades de gêneros.

\begin{abstract}
This text contains fragments of research movements in education. The movements are marked by readings and scriptures that stir ideas. The research embraces the philosophy of difference and the thinking of Deleuze, Butler and Corazza among possible plans of composition in the anguish of problematizing the performativities of genders that constitute lives, especially phallogocentrism. To this end, investigative experiments were carried out with children attending elementary school. Experiments are non-preexisting experiences invented in the everyday life of the school. We left history to enter life, life as an affirmation and will to power that reverberates with binary systems of domination. Thus, we found child dissidences over acts of genders performativities through writing workshops that resulted in critical writing-readings and creators of new ways of thinking, seeing and feeling life and Education.
\end{abstract}

Keywords: Children. Dissidences. Education. Writings-readings. Gender of performativities.

\section{Para citar - (ABNT NBR 6023:2018)}

SOUZA, Edilma de; MONTEIRO, Silas Borges. Dissidências crianceiras: involução criadora em sala de aula. Eccos - Revista Cientifica, São Paulo, n. 53, p. 1-20, e16566, abr./jun. 2020. Disponível em: https://doi.org/10.5585/eccos.n53.16566. 


\section{Alento}

Meninas são poderosas!

(Arto, 10 anos)

Não podemos duvidar da força e inteligência das meninas.

(Jiren Full Power, 11 anos)

As mulheres irão salvar o mundo.

(Mc Bella, 10 anos)

(Escritas-leituras do dia 08/05/2019)

Começamos este texto com uma escritura afirmativa de acontecimentos crianceiros de artistagem na educação. As afirmativas são movimentos acontecimentais de uma pesquisa em Educação sob a chancela da Universidade Federal de Mato Grosso - UFMT. O texto é um convite a um experimento de pensamento tortuoso que consiste em apresentar atravessamentos do ler-escrever infantil que subvertem as performatividades de gêneros que assombram a constituição das subjetividades crianceiras. Não queremos, com este texto, oferecer certezas e postulados úteis com respostas seguras, e sim, trazemos a incerteza de pensamentos nãodominantes para serem questionados e problematizados.

Nos distanciamos da pretensão dos discursos objetivados, universais e sistêmicos que, por sua vez, apreendem em estabelecer "uma verdade" e convidamos os leitores a produzirem efeitos de sentidos. Como nos incita Larrosa (2015, p. 07), "temos a sensação de que temos de apreender de novo a pensar e escrever, ainda que para isso tenhamos de nos separar da segurança de nossos saberes, dos métodos e das linguagens que já possuímos (e que nos possuem)". Em conformidade com o autor, vimos produzindo piruetas nas pesquisas com as humanidades, procuramos as insignificâncias do mundo (e as nossas), no sentido de promover a escuta, o sentir, o ver e o viver; objetivamos o encontro com diferentes experiências que nos passa e nos toca a cada novo encontro com o mundo.

Este texto, resultado de uma pesquisa, proporciona a escuta das coisas, no caso, a escuta dos aprendimentos dos habitantes da escola. Nos propusemos a escutar crianças para conseguinte ressoar suas palavras no campo educacional. Dispusemo-nos no acontecer cotidiano da sala de aula e trazemos para este texto algumas considerações do que ouvimos e sentimos no processo de pesquisa-ensaística-educacional realizado entre as crianças. Percorremos por rotas cheias de agenciamentos e conotações que bifurcaram em problematizar a seguinte questão: Como as crianças provocam fugas e escapes sobre os atos de performatividades de gêneros que preenchem suas subjetividades? 
Portanto, realizamos um percurso investigativo no sentido de desterritorializar discursos heroicos e retumbantes para viver a experiência inventiva, sensível e criativa da infância que produz a diferença. Tomamos novos rumos e construímos novos pensamentos que se abrem ao que acontece no fazer/viver/sentir as vivências que nos constituem. Nos caminhos dos processos de diferenciação da criação infantil encontramos o deslocamento de posições que foram destinados a nós, adultos, praticantes de cotidianos e donos da arrogância da vontade de saber e poder. No acontecimento da pesquisa, levamos em consideração o ponderamento poético de Manoel de Barros (2010, p. 469) quando afirma “com certeza, a liberdade e a poesia a gente aprende com as crianças".

\section{Atravessamentos}

Saboreando as tramas e os saberes que encontramos num processo de pesquisa, não nos detemos em procurar pelo início ou o fim, mas o que acontece entre. O entre surge nos processos de descontinuidades do que é considerado racional e formal. A palavra entre não indica apenas uma posição ou lugar, indica o movimento acontecimental distinto entre elementos, coisas, pessoas, como por exemplo: escola e crianças. Tão próximos e tão afastados, pois ao mesmo tempo em que a escola recebe as crianças no intuito de prepará-las para a vida, por muitas vezes, encontra-se afastada de suas vivências, uma vez que seus modos de funcionamento se constituem de maneiras afins e não consideram o que está entre nessa relação.

O entre para os filósofos Deleuze e Guattari é a acepção de estar intermezzo, inter-ser e produzir alianças que convergem em criar meios e modos de agir. Nas palavras dos autores, "entre as coisas não designa uma correlação localizável que vai de uma para outra e reciprocamente, mas uma direção perpendicular, um movimento transversal que as carrega uma e outra, riacho sem início nem fim, que rói suas duas margens e adquire velocidade no meio" (DELEUZE E GUATTARI, 1995, capa do livro). Assim, entre, fomos conduzidos, saboreando acontecimentos e tecendo redes de saberes e fazeres na criação de possibilidades outras para o aprender e/ou pensar.

Adentramos a sala de aula de uma turma de quinto ano de uma escola pública e atuamos entre as crianças na busca de um potente e feliz encontro. Deslocamos nossos pensamentos para aquele momento, pois "pesquisar com crianças é se deixar levar por diferentes fluxos e viver a experiência da não compreensão - a criança provoca o pensamento e nos força a pensar" (PEREZ, 2014, p. 111), considerando as assertivas da autora, compreendemos que a criança é o outro de nossos pensamentos que escapa das formas preestabelecidas por discursos 
hegemônicos. Os infantis produzem linhas de fuga no cotidiano de suas vivências, suspende o já sabido e nos obriga a negociar as compreensões, as rupturas e a produzir novos agenciamentos na pesquisa e na escola.

Em acordo com o pensamento de Corazza (2013, p. 36), a investigação realizada "tratase de uma pesquisa que investiga o conhecimento, no sentido deleuziano, como aquilo que não é nem uma forma, nem uma força, mas uma função". Sendo então sobre os processos de subjetivação que atravessam os corpos infantis e entre esses processos as crianças encontram forças e formas para dizer sobre, de tal maneira, que outras pessoas possam escriturar sentidos ao ler. Ora, minimamente para que, ao modo de Nietzsche, a pesquisa com crianças funcione como uma flecha ao ferir e ultrapassar as velocidades e as lentidões que nos constituem. Nessa pesquisa do acontecimento, foram realizadas oficinas críticas de escrileituras num processo de involução criadora na educação, pois subsiste entre as formas visíveis e no que acontece na superfície. As oficinas de escrileituras ${ }^{1}$, conforme sinaliza a autora Corazza (2013, p. 35), propõem "uma nova maneira de sentir, uma nova maneira de pensar". Esse gesto oferece impulsos para que concerne na Educação novos meios de expressão que reverberem posições e possibilitem novas maneiras de sentir, fazer, criar, conhecer e saber.

Para Olini (2016, p. 10.719),

As escrileituras [fazem] referência à vida cotidiana, a situacionalidade histórica na qual ela se desenvolve, as relações entre o saber e o poder permitem dar a ver um currículo que não está preocupado com planos administrativos e com a fabricação e homogeneização de sujeitos, mas sim com uma formação aberta aos fluxos e intensidades do pensamento.

As escrileituras oportunizam a experimentação do pensamento e, o desejo de lerescrever, oferecem o exercício de práticas de leituras e produções de textos que exploram a criticidade frente a textos, traduções literárias, poéticas e outras mídias, "compreendem modos plurais de intervenção, nas formas de ensinar e de aprender a ler e a escrever" (CORAZZA, 2015, p. 319), por esse processo de produção de escrileituras é possível ler, escrever e ressoar pensamentos, sentimentos e sentidos num movimento criador que vivifica o currículo, a escola e a vida.

Esses processos vêm acompanhados sob a perspectiva do método da dramatização, visando encontrar nas singularidades infantis os movimentos criativos de resistência aos atos de performatividade de gêneros que ditam modos de ser, estar, sentir e vivenciar o mundo. Proposto por Deleuze (2006) na obra A ilha deserta e outros textos (textos e entrevistas 19531974), o método da dramatização é um exercício do pensamento filosófico: leitura, compreensão, análise e produção do pensamento. Nas assertivas de Corazza (2013, p. 45), “o 
método importa para tomar distância epistemológica representacional, levando o pensamento a capturar forças, numa semiótica da sensação e numa física dos afectos”.

Dessa maneira, não requer explorar mecanismos totalizantes do devir humano, introduz uma nova maneira de explorar o espaço-tempo da pesquisa, imbuindo os participantes numa tarefa dialógica que exige da percepção e da sensibilidade atuarem mutuamente na criação de saberes, fazeres e devires outros, não há neutralidade. Na dramatização agencia-se "movimentos e vibrações de afectos; encontros com hecceidades e variação de potências; relações complexas de velocidades e lentidões, movimento e repouso entre moléculas e partículas" (CORAZZA, 2013, p. 46). Os colaboradores da pesquisa agem reciprocamente e deixam-se afetar e ser afetado; são sensíveis aos movimentos informes de cada participante; fogem dos aparatos metodológicos tradicionais e previsíveis para compor um status criativo, ativo, instável e sensível (corpos sem órgãos).

O método da dramatização envolve processos de diferenciação, "que deve dar sentido a questões das quais partimos" (DELEUZE, 2006, p. 113). Deleuze chama a atenção para as questões que muitas vezes nos levam para significados platônicos ao procurarmos por uma solução geral às coisas, enfatiza que perguntas como $O$ que é? não concerne em um boa questão para descobrir algo; o autor coloca que questões do tipo: quem?, quanto?, como?, onde?, quando?, "são melhores" para estabelecermos processos dinâmicos de diferenciação que surgem durante a pesquisa.

Os dinamismos são espaços-temporais com várias propriedades, nas palavras do autor,

$1^{\circ}$, eles criam espaços e tempos particulares; $2^{\circ}$, eles formam uma regra de especificação para os conceitos que, sem eles, permaneceriam incapazes de se dividirem logicamente; $3^{\circ}$, eles determinam o duplo aspecto da diferenciação, qualitativo e quantitativo (qualidades e extensos, espécies e partes); $4^{\circ}$, eles comportam ou designam um sujeito, mas um sujeito "larvar", "embrionado"; $5^{\circ}$, eles constituem um teatro especial; $6^{\circ}$, eles exprimem ideias. - Sob todos esses aspectos, eles figuram o movimento da dramatização (DELEUZE, 2006, p. 112, grifos do autor).

Os movimentos da dramatização consistem em traçar ideias num processo de diferenciação estabelecendo pontos singulares de enunciação. Deleuze (2006), toma a ideia como multiplicidades para pensar as diferenças em si mesmas sem as categorias de representação. A dramatização (ou processos dinâmicos) produz um cenário no qual os participantes da pesquisa, por meio da fabricação de conceitos, dramatizam as ideias. 
Os dinamismos são tanto temporais quanto espaciais. Eles tanto constituem tempos de atualização ou de diferenciação quanto traçam espaços de atualização. Não só espaços começam a encarnar as relações diferenciais entre elementos da estrutura recíproca e completamente determinados, mas tempos de diferenciação enganam o tempo da estrutura, o tempo da determinação progressiva. Tais tempos podem ser chamados ritmos diferenciais, em função de seu papel na atualização da ideia (DELEUZE, 2006, p. 207).

O dinamismo visa agir, fazer, pôr em movimento; atualizar o que aparece na superfície do pensar e substituir o logos por um drama. As ideias são reais sem serem atuais, ou seja, são moventes num processo de vir-ser-aí. "Pela dramatização, a filosofia da diferença rompe com o pensamento enquanto um universal abstrato, atemporal, neutro, moralmente comprometido, sendo tramado por configurações de forças” (CORAZZA, 2013, p. 58). Com a dramatização há a possibilidade de se pesquisar aspectos curriculares e didáticos na educação para além dos métodos tradicionais, abrem-se novos espaços para problematizar os modos minoritários de vida, explorar a criticidade e o prazer de pensar.

Assim, por esse método na pesquisa, foram produzidos alguns dinamismos, como: 1) Acontecimento; 2) Plano de composição; e, 3) Literaturização da ciência. A organização destes dinamismos possibilitou um novo modo de pesquisar e pensar, o que proporcionou o deslocamento das posições dos participantes da pesquisa na intenção que percebessem e vivessem as diferenças no campo de investigação. Portanto, criaram-se outros caminhos metodológicos na busca de encontrar processos não-embrionários, irrepetíveis e nãosegmentados.

1) Acontecimento: no acontecimento do devir-pesquisa semeia-se ideias e provoca o pensamento que escapa de possíveis hipóteses dedutivas. Para Deleuze, o acontecimento é efeito de superfícies, impossíveis de serem capturados, "ele [o acontecimento] é o que deve ser compreendido, o que deve ser querido, o que deve ser representado no que acontece" (DELEUZE, 1974, p. 152). No acontecimento, o espaço-tempo da pesquisa se desenvolve ao mesmo tempo em que seus participantes agem entre si, "age, despojados de qualquer significado prévio, pois forma-se na anulação dos referentes externos e nos sentidos transcendentes anteriormente construídos" (CORAZZA, 2013, p. 36). O agir resulta em estabelecer relações entre o pensar, o criticar, o sentir, o ler e o escrever, o que resulta na criação de sentidos no que acontece. "O brilho, o esplendor do acontecimento, é o sentido. O acontecimento não é o que acontece (acidente), ele é 'no que acontece' o puro expresso que nos dá sinal e nos espera" (DELEUZE, 1974, p. 166, grifo nosso). O acontecimento só pode ser aprendido no momento que acontece, isto é, sobre os efeitos da superfície. Nas palavras do autor: 
Os acontecimentos, na sua diferença radical em relação as coisas, não são mais em absoluto procurados em profundidade, mas na superfície, neste tênue vapor incorporal que se desprende dos corpos, película sem volume que os envolve, espelho que os reflete, tabuleiro que os torna planos (DELEUZE, 1974, p. 26).

Como afirma Deleuze, "não há nada para se ver por trás da cortina” (DELEUZE, 1974.), e isso é acontecimento, pois tudo está visível ao longo da superfície, é necessário deslizar a tal ponto que a 'profundidade das coisas' seja reduzida ao sentido inverso da superfície. Deste modo, não há dentro e fora, existem forças e fluxos que se misturam mutuamente num instante que de tão fugidio que nunca está aí, está sempre em vias de ser-aí. O acontecimento na investigação é um dinamismo criador de eventos que perpassa entre seus participantes e valoriza os devires, os nomadismos e as atualidade por vir.

2) Plano de composição: Na filosofia de Deleuze e Guattari (2010), o plano é um recorte sobre o caos. $\mathrm{O}$ caos, diferente do que o significam, potencializa a capacidade de agir. "A ciência tem uma maneira muito diferente de abordar o caos, quase inversa: ela renuncia ao infinito, à velocidade infinita, para ganhar uma referência capaz de atualizar o virtual.” (DELEUZE; GUATTARI, 2010, p. 140). Trata-se de um plano para enfrentar o caos que habita a sala de aula e encontre novos modos de pensar/saber/fazer. O plano é, portanto, um espaçotempo movediço onde se dão os acontecimentos. O plano de composição é um plano onde se capturam as sensações, os afectos e perceptos das composições estéticas com arte, mídia, monumentos etc., o que instiga a habilidade criativa no espaço-tempo vivido. Para Deleuze e Guattari (2010, p. 194),

As sensações, perceptos e afectos, são seres que valem por si mesmos e excedem qualquer vivido. Existem na ausência do homem, podemos dizer, porque o homem, tal como ele é fixado na pedra, sobre a tela ou ao longo das palavras, é ele próprio um composto de perceptos e afectos. A obra de arte é um ser de sensação, e nada mais: ela existe em si.

No plano de composição, os perceptos e os afectos atualizam e se encarnam nos processos de diferenciação de nós mesmos, alguma coisa muda no que acontece, na superfície, transborda e produz devires, resistências como também a metamorfose. No plano, nos tornamos Outros em nossas relações de saber e poder, um Outro enquanto Outro, diferente daquilo que podemos antecipar. No plano de composição, encontram-se movimentos que expulsam os clichês abordados em pesquisas e em algumas práticas educativas, entendendo que nos clichês nada se cria, tudo se copia e reapresenta. Deste modo, com nossos personagens estéticos, encontramos um cenário de possibilidades imbuído de novas sensações para artistar na educação como a produção de escrileituras que citaremos mais adiante, engendrando a 
construção da inventividade das infâncias e, encontrarmos também, os cheiros das coisas, das meninices e das árvores como lembra Manoel de Barros (2010).

A partir disso, entre as crianças, a sala de aula e a produção de escritas-leituras, compomos e escrevemos sensações. As sensações são um composto de perceptos e afectos. "Os perceptos não mais são percepções, são independentes do estado daqueles que o experimentam; os afectos não são mais sentimentos ou afecções, transbordam a força daqueles que são atravessados por eles" (DELEUZE; GUATTARI, 2010, 193). Somos atravessados e contagiados por perceptos e afectos que se manifestam por si mesmo diante de algum acontecimento e nos conduzem a criar sentidos, metamorfoseia nossos pensamentos e potencializa nossa capacidade de agir, “a sensação não é colorida, ela é colorante (DELEUZE; GUATTARI, 2010, p. 197). A sensação potencializa nossa habilidade de sentir, ver e viver um acontecimento e dizer a partir dele. "Os afectos são precisamente estes devires não humanos do homem [..] Não estamos no mundo, tornamo-nos com o mundo, nós nos tornamos contemplando-o" (DELEUZE; GUATTARI, 2010, p. 200). Tudo é visão, devir e sentir, estamos em constante processo de vir-ser-aí diante de tudo que o caos nos provoca. $\mathrm{O}$ enfrentamento do caos é composto por devires que se manifestam de diferentes posições, acontecimentos e planos de composição. "Devires animal, vegetal, molecular, devir zero" (DELEUZE; GUATTARI, 1995). O devir trata de liberar forças e fluxos de mudanças lá onde estamos prisioneiros/as.

O plano de composição, por si mesmo, apresenta afectos e perceptos, nos engole em sua obra e cria condições para diferir, problematizar e duvidar no caos, ele nos apanha em sua composição de sensações e nos faz gritar, cantar, produzir, escrever, compor e exalar nossos pensamentos. Como o poeta que torce a linguagem e a faz vibrar, como Barros que em sua poética explicita "desver o mundo para encontrar nas palavras novas coisas de ver" (BARROS, 2010, p. 449).

3) Literaturizar a ciência: Este movimento tomamos emprestado da autora Nilda Alves que faz a seguinte ressalva,

É preciso outra escrita para além da já aprendida. Há assim, outra escritura a aprender: aquele que talvez se expresse com múltiplas linguagens (de sons, de imagens, de toques, de cheiros, etc.) e que, talvez, não possa mais ser chamada de "escrita"; que não obedeça à linearidade de exposição, mas que teça, ao ser feita, uma rede de múltiplos, diferentes e diversos fios; que pergunte muito além de dar respostas; que duvide no próprio ato de afirmar, que diga e desdiga, que construa outra rede de comunicação, que indique, talvez, uma escritafala, uma falaescrita ou uma falaescritafala (ALVEZ, 2015, p. 145, grifos da autora). 
Corroborando o que diz a autora, entendemos que é necessário revolucionar os modos aprendidos com a ciência moderna, pois, nos últimos séculos, aprendemos que para produzir conhecimentos é preciso separar o sujeito do objeto para estudo. Entendemos, em nossa lida cotidiana de pesquisa em Educação, que as virtualidades da modernidade foram [e ainda são] profícuas em muitos casos investigativos, no entanto, a cada novo encontro com as diferenças surgem novas demandas, novos modos diferentes e variados que se misturam e convergem em outros modos de ver/pensar/falar/sentir/viver. Para esses outros modos é possível desacostumar os olhos para enxergar nelas novas coisas e encontrar o ínfimo e as incertezas que colocam sob suspeita as nossas verdades.

Destarte, literaturizar a ciência é um convite ao pesquisador a mudar a rota quando necessário e buscar novos meios para soar os conhecimentos/saberes/fazeres que surgem durante a pesquisa, ou seja, aquilo considerado "resto" pela ciência moderna. Podemos literaturizar a ciência com contos, cheiros, sabores e saberes cotidianos de nossas vivências, ditas e escritas por pessoas comuns, assim como fez Nietzsche com seu Zaratustra. A obra do filósofo da suspeita, Assim falou Zaratustra, escrita entre os anos de 1883-1885, é um livro que repercutiu mundialmente sua crítica aos valores e ideias da sociedade moderna a partir de um personagem que expunha sua crítica em suas narrativas.

Eu caminho entre os homens como entre pedaços de um futuro: aquele futuro que enxergo. E este é todo o meu engenho e esforço, eu componho e transformo em um o que é pedaço, enigma e apavorante acaso. E como suportaria eu ser homem, se o homem não fosse também poeta, decifrador de enigmas e redentor do acaso? (NIETZSCHE, Assim falou Zaratustra, Da redenção).

A obra Zaratustra aponta para outros caminhos possíveis e demonstra que é possível literaturizar a ciência com conhecimentos e sabedorias comuns a partir dos aprendimentos, das criações e das sensibilidades das pessoas anônimas. Como diz a autora Corazza (2013), a partir das artistagens inventivas dos participantes da pesquisa é viável a fabricação de novos sentidos e conhecimentos. Isso porque no experimento realizado são ensaiadas novas relações entre os participantes, construídas novas composições; uma dramatização do pensamento, irrepetível, fazendo do "[...] pensamento um plano de composição onde os acontecimentos se tecem e destecem" (TADEU; CORAZZA; ZORDAN, 2004, p. 68). Dessa maneira, os participantes têm a oportunidade de criar e inventar momentos de continuidade e descontinuidade de suas vivências e como diz o poeta Barros (2010, p. 470) "encher os vazios com as suas peraltagens". 


\title{
Artistagens crianceiras
}

$\mathrm{Na}$ intenção de não compormos uma totalidade para a vida desenvolvemos pesquisas com crianças que nos colocam sob a espreita de nossas certezas. As crianças manifestam seus efeitos crianceiros sem o propósito da fixação de normas e regras, vivem titubeando entre acontecimentos, planos de composição e agenciamentos cotidianos de subjetivação, sem darem conta do que estão fazendo, apenas estão se tornando, sendo-aí uma hecceidade (individuação) sem sujeito que pulula com a vida ordinária. As crianças criam astúcias, tomam atitudes, formam armadilhas e restituem a palavra emudecida que nós, adultos, insistentemente queremos calar. As crianças vivem a possibilidade de "interpelar a história, a história oficial da criança e da infância por meio de seus fragmentos" (MALDONADO, 2014, p. 125, grifos nossos).

Por meio dos fragmentos das infâncias, que constituem nossos cotidianos, nos aproximamos das infantilices e dos momentos crianceiros singulares e irrefazíveis pois, as crianças e suas infâncias, é algo que sempre nos escapa: "na medida em que inquieta o que sabemos (e inquieta a soberba de nossa vontade de saber), na medida em que suspende o que podemos (e a arrogância da nossa vontade de poder)" (LARROSA, 2015, p. 185). As crianças e as infâncias colocam sob suspense nossos devaneios e delírios de sempre "saber o que fazer com elas", resistem aos nossos planos de captura de suas singularidades ao momento que conseguem questionar nossas práticas de acolhimento.

\begin{abstract}
A infância nunca é o que sabemos (é o outro de nossos saberes) mas, por outro lado, é portadora de uma verdade à qual devemos nos colocar à disposição de escutar; nunca é aquilo apreendido pelo nosso poder (é o outro que não pode ser submetido), mas ao mesmo tempo requer nossa iniciativa; nunca está no lugar que a ela reservamos (é o outro que não pode ser abarcado), mas devemos abrir um lugar para recebê-la (LARROSA, 2015, p. 186).
\end{abstract}

A alteridade da infância está naquilo que não sabemos dela, por isso só podemos dizer sobre a marca de seus rastros, aguçar nossa sensibilidade de escutá-las e oferecer a elas lugares (no plural) que reverberem suas meninices e peraltagens infantis para que possam viver e expandir a experiência da infância artista e criativa de suas singularidades, para que com isso possam criar suas experiências infantis e potencializar a vida. A vida como afirmação e vontade de potência.

E sabeis sequer o que é para mim “o mundo"? Devo mostrá-lo a vós em meu espelho? Este mundo: uma monstruosidade de força, sem início, sem fim, uma firme, brônzea grandeza de força, que não se torna maior, nem menor, que não se consome, mas apenas se transmuda, [...] - Esse mundo é a vontade de potência - e nada além disso! E também vós próprios sois essa vontade de potência - e nada além disso (NIETZSCHE, Fragmento Póstumo, 38 [12] junho - julho de 1885). 
A vida é vontade de potência. Para Nietzsche, trata-se de um complexo jogo de forças que estão permanentemente em conflitos. Nesse jogo de forças, as crianças não interpretam relações e situações, agem por devires e criam, desconstroem a universalidade da linguagem, como também, os atos de repetição estilizados na performatividade de gênero que persuadem sobre seus corpos. As crianças com sutileza e admiração pelo mundo, reverberam conceitos e teorias que se valem de "um lugar para o menino" e/ou "um lugar para a menina", pois, estão estritamente ligados à vida.

As crianças tornam outros pensamentos possíveis com perspectivas políticas que suscitam a capacidade de diferir,

Um pensamento às voltas com forças externas em vez de recolhido numa forma interior, operando por revezamento em vez de formar uma imagem, um pensamentoacontecimento, 'hecceidades', em vez de um pensamento-sujeito, um pensamentoproblema no lugar de um pensamento-essência ou teorema, um pensamento que faz apelo a um povo em vez de se tomar por um ministério (DELEUZE e GUATTARI, 1997, p. 48).

Para Deleuze e Guattari, pensar é resistir, é criar fluxos de forças cósmicas que vão do impossível ao verdadeiro, é desacordar de onde estamos, questionar e/ou problematizar o que vem sendo dado como realidade dominante. Os filósofos, consideram o pensar como um movimento desterritorializante dos pensamentos já assistidos, pensar o próprio pensamento possibilita a produção de ideias criadoras. As crianças assim fazem, deslocam o pensamento para criar outras performances, novos conceitos, novos movimentos e artistam com aquilo que podem. Nesse movimento, criam encontros e experiências no plano de composição de suas vidas.

Os processos de invenção infantil escritos neste texto, reportam-se a experiência "entendida como uma expedição em que se pode escutar o "inaudito" e em que se pode ler o não-lido, isso é, um convite para romper com os sistemas de educação que dão o mundo já interpretado, já configurado de uma determinada maneira, já lido e, portanto, ilegível” (LARROSA, 2015, p. 10-11, grifos do autor). No espaço-tempo de vivência infantil vivenciase momentos de desterritorialização que solicita a abertura para outros sentidos, permite-se lerescrever com as crianças na produção da diferença e, no plano de composição do devir-criança, estilhaça-se com a forma dada e consolidada.

O devir-criança é uma forma de encontro que marca uma linha de fuga a transitar, aberta, intensa. Devir-criança é, assim, uma força que extrai, da idade que se tem, do corpo que se é, os fluxos e as partículas que dão lugar a uma "involução criadora", a "núpcias antinatureza", a uma força que não se espera, que irrompe, sem ser convidada ou antecipada (KOHAN, 2007, p. 97, grifos do autor). 
O devir-criança salta por linhas desestratificadas de modos de subjetivação, inventa, dá lugar para uma involução criadora, produz cadências as coisas e as palavras inaudíveis, misturase com as multiplicidades, compõe-se entre as margens dos limites delineados e provoca novas ideias, pensamentos, desejos, sons, silêncios e devires-outros. O devir-criança corrompe o status quo e, por assim entendermos, deslizamos entre vinte duas crianças que frequentam o quinto ano da educação básica numa escola estadual situada no interior do estado de Mato Grosso - MT, em vias de vivenciar o plano de composição da sala de aula infantil, experenciar os contos, as conversas, os jogos de saber e poder, a irreverência dos acontecimentos infantis, os gestos intempestivos dos movimentos das crianças e os desafios dos processos de desterritorializações vividos. Vivemos um pouco do sentimento expresso na poética de Antoine de Saint-Exupéry (2009) em $O$ Pequeno Príncipe, pois aqueles que passam por nós não vão sós. Deixam um pouco de si, levam um pouco de nós.

Ziguezagueamos entre as feituras da sala de aula experimentando o sabor de apreender e aprender, acomodar e desacomodar pensamentos que se confluem e convergem diante dos ecos infantis. Para tanto, produzimos as oficinas de escrileituras mediadas por filmes de curtasmetragens. Nas oficinas, as crianças foram convidadas a assistirem filmes de curta duração com tempo de exibição de um a oito minutos. Os curtas metragens foram retirados da plataforma Youtube, sendo tais: Heroínas do ano; O sonho impossível (ONU); Mulher Maravilha; O campeonato de videogame (ONU); O desafio da Igualdade; Valente: arco e flecha. As crianças assistiram, problematizaram e, a maneira que se sentiam à vontade, produziram escritasleituras, procurando estabelecer alguma relação com o que foi assistido à suas vivências infantis. Os filmes apresentados esboçaram relações de performatividades de gêneros. As crianças assistiram e depois ressoaram seus pensamentos por meio de seus escritos. Observe:

Mulheres podem ser o que elas quiserem! Minha mãe é uma heroína. Fire Crow, 11 anos $^{2}$. Filme: Heroínas do ano Escrita-leitura do dia 08/05/2019

Portanto, trazemos para este texto as dissidências crianceiras por meio de escritasleituras produzidas nas oficinas. Queremos que as duas oficinas que explicitamos aqui atuem como intercessores para discutirmos que é possível tirar ilações do debate das performatividades de gêneros na escola. A performatividade de gênero pode ser conceituada como prática e teoria com fins de criticar as normatividades (BUTLER, 2015). Nosso interesse nessa temática aponta para as críticas em todos os âmbitos, como a imposição construída 
historicamente e socialmente por ordens de discursos legitimados na heteronormatividade, valores, ideais e morais falogocêntricas - a verdade-homem.

Portanto, por meio dos efeitos da desconstrução da linguagem metafísica, vimos produzindo escrituras às margens do logocentrismo e do pensamento fálico, na tentativa de escapar do que foi aprisionado em um sistema de representação masculinista, isto é, a performatividade de gênero de propagação do falogocentrismo. A cultura do falogocentrismo, termo cunhado por Derrida (2013), legitima a plenitude do homem em detrimento a mulher, essa cultura centraliza o homem como detentor do saber e poder, compõe a história social do ocidente e da metafísica da presença, tendo-o como o centro, ou seja, a plena presença do homem basta para as interpretações do mundo. O argumento falogocêntrico baseia-se na afirmação de que a cultura ocidental moderna, tem sido, e continua a ser cultural e intelectualmente subjugada pelo "logocentrismo" e "falocentrismo". Logocentrismo é o termo que Derrida usa para se referir à filosofia determinista, enquanto falocentrismo é o termo que ele usa para descrever a maneira como o logocentrismo foi generalizado por pressupostos masculinizados (fálico)" e patriarcal. Assim, Derrida intencionalmente funde os dois termos falocentrismo e logocentrismo como "falogocentrismo" (DERRIDA, 2013).

Assim, nosso exercício na pesquisa, voltou-se para a problematização dos atos das performatividades de gêneros que detém o falogocentrismo como modos de normatização dos corpos infantis e buscamos compreender como as crianças, na contemporaneidade, repudiam alguns atos, pois consideramos que as crianças são seres singulares, sensíveis, irrepetíveis e podem inserir no debate educacional novos modos de pensar e agir.

Deslocamos a discussão sobre as performatividades de gênero tendo como referencial a autora Judith Butler e o filósofo Derrida acerca do falogocentrismo. Buscamos por "formas plurais de agência e práticas sociais de resistência” (BUTLER, 2015, p. 09), nas feituras infantis. Pretendemos, mesmo que de forma tateante, falar de uma "democracia do por vir" insurgente no plano de composição da sala de aula e como é possível "transver" o mundo racionalizado por políticas falogocêntricas por meio de microrresistências e microliberdades que almejam janelas para a alteridade.

A abjeção de certos tipos de corpos, sua inaceitabilidade por códigos de inteligibilidade, manifesta-se em políticas e na política, e viver com um tal corpo no mundo é viver nas regiões sombrias da ontologia. Eu me enfureço com as reivindicações ontológicas de que códigos de legitimidade constroem nossos corpos no mundo; então eu tento, quando posso, usar minha imaginação em oposição a essa ideia. [...] com efeito, parece-me crucial recircular e ressignificar os operadores ontológicos, mesmo que seja apenas para apresentar a própria ontologia como um campo questionado (BUTLER, 2002, p. 157). 
Mobilizar o pensamento no intuito de problematizar os contornos das performatividades de gêneros e questionar os seus atos de repetição conta como política de desafirmação da ontologia reconhecida como ideal. Na vida cotidiana, somos subjetivados por políticas ontológicas racionalizadas por discursos totalizantes e heteronormativos que nos conferem um único modo de atuar no social e no privado. Com efeito a essas delimitações, surgem processos maquínicos de objetivação dos corpos validando sua posição na hierarquização social. No entanto, entre a pretensão da política ontológica, reside a premissa de corpos excluídos, corpos que não se renderam a uma extensão da política ontológica universal e reclamam por seus lugares destituídos historicamente pela falta de políticas de inclusão. Isso é o que a autora Butler chama de "estrutura ambivalente da performatividade" (BUTLER, 1997, p. 40).

Ambos os movimentos caminham lado a lado no campo cultural de subjetivação, estamos nos referindo à posição feminina dada as mulheres, posições provindas do binarismo homem/mulher. A mulher numa relação binária ocupa lugares de subalternização e tem seus direitos precarizados sobre os efeitos do falogocentrismo. A performatividade de gênero, mediante a afirmação do falogocentrismo, é uma prática reiterativa e citacional que insere nos corpos ideias, morais e valores representacionais. Nas palavras de Butler, "a performatividade deve ser compreendida não como um "ato" singular ou deliberado, mas, ao invés disso, como a prática reiterativa e citacional pela qual o discurso produz os efeitos que ele nomeia" (BUTLER, 1993, p. 02, grifos da autora). As pessoas, os corpos se constituem através da interpelação do outro, a partir disso, torna-se vulnerável às nomeações e a autoridade de quem nomeia. Os atos de fala delimitam os contornos dos corpos, suas articulações e suas possíveis ações.

Nessa perspectiva, nossos movimentos e nossas sensibilidades voltaram-se para salientar as produções cotidianas que se constituem no fazer e saber infantil e produz no currículo e nas didáticas da escola à passagem da diferença diante do pensamento falogocêntrico. Agenciamos no acontecimento das oficinas de escrileituras e observamos o quanto as crianças subvertem "um télos normativo e definidor" (BUTLER, 2018, p. 37). Abrese, no plano de composição do currículo e da didática que perpassa a sala de aula, espaços da diferença reconhecendo as singularidades e expandindo as multiplicidades.

\section{Oficina 1: Desacostumar os olhos}

Na oficina "desacostumar os olhos" foi exibido o filme "o campeonato de videogame". Sinopse: este filme tem a duração de um minuto e trinta e três segundos e apresenta em seu 
conteúdo meninos que se preparam para um campeonato de videogame. Algumas meninas ficam sabendo e exigem participar, o que gera revolta por parte dos meninos e dispõem da seguinte afirmação: “meninas não podem jogar videogame porque é um jogo de meninos”, esta afirmação gerou a maior discussão, no entanto, entre voltas e revoltas, as meninas participaram do campeonato e foram campeãs.

Do filme assistido, surgiram as seguintes manifestações por vias dos escritos infantis,

Ótima ideia desse vídeo, os meninos não são melhores que as meninas. Temos que acabar com a desigualdade de gênero. Jake risonho, 10 anos.

Meninos e meninas podem brincar juntos, meu primo brinca de panelinha comigo e eu jogo bola com ele. Maíra Caetano, 11 anos. As meninas podem jogar o que elas quiserem. Aquaman, 11 anos.

Sou menina e gosto de jogos de videogame, jogo com meu irmão. As meninas devem participar de jogos e campeonatos e conquistar seu espaço. MC Bella, 10 anos.

(Escritas-leituras do dia 14/05/2019)

Estas escritas-leituras produzidas pelas crianças subverteram a posição destinada a meninos e meninas enquanto seres individuados e subjetivados por discursos falogocêntricos. As crianças rearticularam o horizonte simbólico das posições dadas e produziram a diferença em seus atos de pensar e expor seus pensamentos. Criaram dissidências para além do que lhes foi reservado, pois "as crianças, as mulheres, os loucos os descortina possibilidades nas quais habitualmente não cremos, quando se eleva tal voz de contralto, profunda e poderosa" (DERRIDA, 2013, p. 26). Ao problematizarem o filme, as crianças passam de meros consumidores passíveis de uma linguagem dominante imbricada em relações de poder que contempla o binarismo homem/mulher e criaram entre essa linguagem, assumiram o papel de autores críticos. No acontecimento da oficina de escrileituras realizaram a tradução diferencial do pensamento crítico, artístico, filosófico e científico ao explicitarem a tradução de seus pensamentos (CORAZZA, 2015).

Para a autora Corazza (2015, p. 321), as escritas- leituras, 


\begin{abstract}
Não são guiadas por uma tradutologia ou ciência da tradução, mas por uma poética do traduzir. Poética experimental, que produz efeitos pedagógicos e epistêmicos, contrários ao cientificismo estruturalista, de vocação positivista; e que se operacionaliza como estratégia contra a manutenção dos dogmatismos, sendo inseparável de uma transformação das relações interculturais, propiciadora de encontros e de intercâmbios linguísticos. [...] as traduções são feitas com textos, não exclusivamente com línguas e levantam questões éticas e políticas.
\end{abstract}

Assim, as crianças ao traduzirem seus pensamentos, por intermédio dos filmes, revelaram um pouco dos afectos e os perceptos que constituem suas singularidades, visibilizaram seus pensamentos por meio da liberdade de ler-escrever e traduzir à vida. Nesse viés Corazza indica, "a tradução percorre a DidáticArtista, como um dispositivo que a desencadeia e uma prática que a desdobra. Sua natureza didática passa a ser constituída pela tradução de perceptos, afectos, funções e conceitos (CORAZZA, 2013, p. 209). O movimento criado na produção das escritas-leituras infantis é a arte de sentir, ler-escrever e literaturizar a ciência.

As escritas-leituras, ao literaturizar a ciência, traz traduções carregadas de sentidos que convergem e bifurcam em afirmações da vida criativa e sensível. A vida criativa tem a capacidade de provocar erupções aos modos de ver e sentir, como também, suspender a fé em crenças reacionárias, desafirmar sentidos pré-fixados numa episteme binária como a relação homem/mulher, deslocar posições e inverter hierarquias. Como evidencia Deleuze, "criar não é comunicar, mas resistir. [...] Não há obra que não indique uma saída para a vida, que não trace um caminho entre as pedras" (DELEUZE, 2013, p.183). A arte de ler-escrever é uma tarefa árdua e reveladora de sentidos que apresenta a possibilidade de produzir a fuga das situações de opressão.

\title{
Oficina 2: Transver o mundo
}

"É preciso transver o mundo" como afirma o poeta Manoel de Barros (2010, p. 350), para enxergar a inutilidade das palavras, das frases e dos acontecimentos e enxergar novas coisas ao ver. Olhar as coisinhas do chão [e da educação] com mais sensibilidade e ouvir o inaudito. Nesta oficina foi exibido o filme "O sonho impossível (ONU)", produzido pela Organização das Nações Unidas. Sinopse: o filme (mudo) traz a cena acontecimentos de uma família tradicional moderna que tem no homem a centralidade do poder patriarcal. Nessa família, os afazeres domésticos ficam todos a cargo da mulher. Um dia, a mulher exausta, ao dormir tem um sonho no qual todos na casa dividem e desempenham as tarefas domésticas e ela consegue sair daquela condição de opressão. Como era apenas um sonho, ao acordar se vê naquela condição subalternizada e percebe que nada mudou. Por isso, sonho impossível. 
Diante disso, os estudantes leram e escreveram seus pensamentos:

Uma mulher tem que fazer muitas coisas ao mesmo tempo, igual trabalhar, fazer comida, lavar a louça, tudo o que os homens não fazem. Na minha casa é assim. Eu não gosto disso.

MC Bella, 10 anos.

Só concordo com o sonho porque na vida real é tudo diferente. Os homens não querem fazer a parte deles e deixam tudo para as mulheres. Lá na minha casa todo mundo faz alguma coisa. A minha mãe divide as tarefas.

Monkayse Linda, 10 anos.

É um sonho impossível de se realizar, muitos homens não fazem nada em casa e dizem que é serviço de mulher. Mas se vivem na mesma casa, todos tem que fazer os serviços doméstico, não importa se é homem ou mulher. MC Mirella, 11 anos. Temos que acabar com o machismo. Jake Risonho, 10 anos.

(escritas-leituras do dia 23/05/2019).

Estas traduções produzem o efeito de diferir diante dos discursos falogocêntricos que fazem parte do dia a dia. Para Butler (2018), o corpo está fundado em uma linguagem que opera e faz, sendo assim, o corpo sofre efeitos e é sustentado pela linguagem que determina espaços e posições. Os atos de performatividades ensejam uma produção reguladora e normativa sobre as pessoas. A partir disso, as traduções crianceiras, provindas das oficinas de escrileituras, oferecem a cisão dos aspectos heteronormativos fundados num sistema binário de opressão com os corpos que estão em via de ser-aí. "A tradução didática compartilha línguas heterogêneas e simultâneas, modificando e desfazendo identidades sedentárias" (CORAZZA, 2013, p. 209), a tradução implica a invenção de um status crítico que investe na poética, nos conflitos cotidianos e na literatura, os seus anseios com a função de traduzir aquilo que nos inquieta e apresenta maiores desafios, no caso da pesquisa, a tradução crianceira produz a crítica e a resistência rompendo com as performatividades de gêneros que legitimam a "verdade-homem". Trata-se de contestar e resistir a manutenção de uma estrutura ambivalente, assumindo outras posições que ofereça a possibilidade de pensar diferente do que vem sendo pensado há séculos. “[...] não renunciarmos esses conceitos é que eles nos são indispensáveis hoje para abalar a herança de que fazem parte" (DERRIDA, 1973, p. 16). Os escritos infantis, tanto constrangem quanto produzem dinamismos teóricos e literários como forma de liberar a diferença que constitui suas singularidades. 


\section{Enfim, com fins, sem fins}

Desterritorializar o pensamento para encontrar novas maneiras de pensar é preciso. É necessário sairmos da nossa zona de conforto e buscarmos por novos ares na vida e na Educação. Temos a necessidade, frente o que vimos enfrentando no interior dos espaços-tempos escolares, inventar novas composições que possam dizer e desdizer práticas e discursos ideais e previsíveis, pois há vidas escorregadias, desviadas pelos desejos e afectos intensos que solicitam outros espaços. Artistar na Educação é isso, é trabalhar com a sensibilidade de seus autores para visibilizar suas criações diante de uma linguagem que tenta a todo modo fixar posições e sentidos.

Problematizar as performatividades de gêneros entre as crianças foi explicitar o inaudito de autores críticos que por muito tempo foram silenciados tanto em políticas públicas como na vida social e na Educação. Trazer o acontecimento crianceiro para a pesquisa e ressoar seus pensamentos, oportunizou pensar-se e superar-se diante dos limites e das rotas que temos no campo educacional. As oficinas de escrileituras, na sala de aula, evoca forças que enfrentam as delimitações curriculares, as didáticas e as propostas de silenciamento das diferenças, por vez, propicia a entrada de uma multiplicidade de saberes, fazeres, afectos e perceptos na invenção do cotidiano escolar, traz para o dia a dia a sensibilidade da vida, a literatura e a autopoiése. Por meio dos escritos infantis, foi possível conhecer traduções do vivido sensível, dado que as crianças criaram outras sensibilidades além da instituída e ultrapassaram territórios identitários marcados por políticas de performatividades de gêneros que privilegiam o falogocentrismo.

Longe da pretensão de produzir uma verdade, entendemos que é possível criar microliberdades e microrresistências na Educação e na vida vivível para que confronte políticas ontológicas deterministas que ditam maneiras de ser e estar no mundo. Longe de um final feliz, trata-se de não esterilizar a diferença, mas usá-la em sua produtividade e potenciais conexões que permitam romper com as ordens discursivas que validam posições binárias. Enfim, ressoar a palavra dos autores da educação, com fins de visibilizar seus pensamentos e feituras provindos de uma clínica do pensar, do ler-escrever, do educar, do viver, da ordem do sensível, sem fins. 
${ }^{1}$ As oficinas de escrileituras tem como fundamento teórico-epistemológico os estudos da Professora Dra. Sandra Mara Corazza da Universidade Federal do Rio Grande do Sul.

${ }^{2} \mathrm{Na}$ realização das oficinas de escrileituras as crianças tiveram a oportunidade de criar um nome fictício. Os nomes fictícios estão em conformidade com o estabelecido nos termos de Assentimento e Consentimento Livre Esclarecido do Comitê de Ética e Pesquisa (CEP).

\section{Referências}

ALVES. N. Praticantepensante de cotidianos. Belo Horizonte: Autêntica, 2015.

BARROS, M. de. Poesia completa. São Paulo: Leya, 2010.

BUTLER, J. Bodies that matter: on the discursive limits of 'sex'. New York, Routledge, 1993.

BUTLER, J. Excitable speech: a politics of the performative. New York, Routledge, 1997.

BUTLER, J. Como os corpos se tornam matéria: entrevista concedida à Bauke Prins e Irene Costera Meijer. Revista Estudos Feministas, v. 10, n.1, p.155 - 167, 2002.

BUTLER, J. Notes toward a performative theory of assembly. Cambridge: Harvard University Press, 2015.

BUTLER, J. Problemas de gênero: feminismo e subversão da identidade. Tradução de Renato Aguiar. Rio de Janeiro: Civilização Brasileira, 2018.

CORAZZA, S.M. O que se transcria em educação. Porto Alegre: UFRGS, 2013.

CORAZZA, S. M.; RODRIGUES, C. R.; HEUSER, E.M.D.; MONTEIRO, S.B. Didática da tradução: transcriações do currículo no projeto Escrileituras. Revista de Educação Pública, Cuiabá, v. 24, n. 56, p. 317-331, 2015.

DELEUZE, G. Lógica do Sentido. Tradução de Luiz Roberto Salinas Fortes. São Paulo: Perspectiva, Ed. da Universidade de São Paulo, 1974.

DELEUZE, G. A ilha deserta e outros textos: Textos e entrevistas (1953-1974). Tradução de Luiz B. L. Orlandi. São Paulo: Iluminuras, 2006.

DELEUZE, Gilles. Conversações (1972-1990). Tradução de Peter Pál Pelbart. 3.ed. São Paulo: Ed. 34, 2013.

DELEUZE, G; GUATTARI, F. Mil platôs: capitalismo e esquizofrenia. São Paulo: Ed. 34, v.1, 1995.

DELEUZE, G; GUATTARI, F. Mil platôs: capitalismo e esquizofrenia, vol 5. São Paulo: Ed. 34, 1997.

DELEUZE, G. GUATTARI, F. O que é a filosofia? Tradução Bento Prado Jr. e Alberto Alonso Muñoz. São Paulo: Ed 34, 2010. 
DERRIDA, J. Gramatologia. Tradução: Miriam Schnaiderm e Renato Janini Ribeiro. São Paulo: Perspectiva, 1973.

DERRIDA, J. Esporas: Os estilos de Nietzsche. Tradução Rafael Haddock - Lobo e Carla Rodrigues. Rio de Janeiro: NAU, 2013.

Heroínas do ano, 2016. 1 vídeo (2min. 19 segs.). Publicado pelo canal High World. Disponível em: https://www.youtube.com/watch?v=1Qr0EAdxgEk. Acesso em: 4 de março de 2019.

KOHAN, W. O. Infância, estrangeiridade e ignorância: ensaios de filosofia e educação. Belo Horizonte: Autêntica, 2007.

LARROSA, J. Pedagogia Profana: danças, piruetas e mascaradas. Tradução Alfredo Veiga Neto. Belo Horizonte: Autêntica Editora, 2015.

MALDONADO, M.M.C. Saberes ribeirinhos: o pantanal dobrado na alma das crianças que o habitam. In: RIBETTO, A. (org.). Políticas, poéticas e práticas pedagógicas (com minúsculas). Rio de Janeiro: Lamparina, FAPERJ, 2014.

NIETZSCHE, F. Assim falou Zaratustra: um livro para todos e para ninguém. Tradução Paulo César de Souza. São Paulo: Companhia das Letras, 2011.

NIETZSCHE, F. Fragmentos Póstumos. 1884-1885. Tradução Marco Antônio Casanova. Rio de Janeiro: Forense Universitária, 2015.

O CAMPEONATO DE VIDEOGAME (ONU), 2018. 1 vídeo (1 min. 33 segs.). Publicado pelo canal De criança para criança. Disponível em:

https://www.youtube.com/watch?v=31ZWPvfk9EM. Acesso em: 9 de set. de 2018.

O SONHO IMPOSSÍVEL (ONU), 2012. Produzido por Studio J. Trnka Kratky Films, Praga (República Tcheca) em parceria com as Nações Unidas. 1 vídeo (8 min.16 segs.). Disponível em: https://www.youtube.com/watch?v=dKSdDQqkmlM\&t=409s. Acesso em: 04 de jun. de 2018.

OLINI, P.; CORAZZA, S. M. Noologia do currículo: dramatizações do projeto escrileituras. Currículo sem Fronteiras, v. 16, n. 3, p. 559-577, set./dez. 2016.

PÉREZ, C. L. V. Cinco cabeças e um copo de café...(com) fabulações sobre a potência de uma educação menor. In: RIBETTO, A. (org.) Políticas, poéticas e práticas pedagógicas (com minúsculas). Rio de Janeiro: Lamparina, FAPERJ, 2014.

SAINT-EXUPÉRY, A. O pequeno príncipe. Rio de Janeiro, Editora Agir, 2009.

TADEU, T.; CORAZZA, S. M.; ZORDAN, P. Linhas de Escrita. Belo Horizonte: Autêntica, 2004. 